\title{
Children Activities in Public Housing
}

\author{
Nurul Liyana Hanapi, Sabarinah Sh Ahmad \\ Centre of Studies in Architecture, Faculty of Architecture, Planning \& Surveying, \\ Universiti Teknologi MARA, Shah Alam, Malaysia \\ Liyana513123@gmail.com
}

\begin{abstract}
When living in a high-density public housing, children, and physical activities might be an issue as the physical environment may inhibit their outdoor activities. The objective of this paper is to focus on the impact of the physical environment in public housing which affects the children's physical activity inhibitive. The method employed is mainly through a literature review of published article and journal. There is four distinguished physical characteristic that highlighted in this paper. Poor safety, crowding, limited facilities and poor neighbourhood relationship prove to contribute less physical activities to the children.
\end{abstract}

Keywords:physical activities; public housing; neighbourhood; poor safety

eISSN: 2398-4279 @ 2017. The Authors. Published for AMER ABRA by e-International Publishing House, Ltd., UK. This is an open access article under the CC BY-NC-ND license (http://creativecommons.org/licenses/by-nc$n d / 4.01$ ). Peer-review under responsibility of AMER (Association of Malaysian Environment-Behaviour Researchers), ABRA (Association of Behavioural Researchers on Asians) and $c E-B s$ (Centre for EnvironmentBehaviour Studies), Faculty of Architecture, Planning \& Surveying, UniversitiTeknologi MARA, Malaysia. https://doi.org/10.21834/ajqol.v2i5.6 


\subsection{Introduction}

Higher cost and acute shortage for landed public properties increase the demand for multistorey public housing in the urbanising area. The public building is well sought after due to lower cost and maintenance during occupancy. $60 \%$ of the occupancy are mainly from the low-income family with many children (Currie \& Yelowitz, 2000). The high number of children in the limited land area will result in less physical activities. It is believed that children with poor social and physical activities lead to an adverse effect that will perceive throughout life ultimately affecting their future.

\subsection{Literature Review}

Safety issues are one of the reasons parents nowadays uses technology as a medium to control their children. These parents did not see the negative impact it will bring to the children in the long run when they are abusing the technology. It will result in less outdoor activities of the children and become more prone to several health issues. When they are not trained to be physically active, not only the health issues will become the problem but it will cause a problem in their social development (Boldemann et al., 2011; Carver, Timperio, \& Crawford, 2008; Harmon et al., 2014; van Loon, Frank, Nettlefold, \& Naylor, 2014).

The limitation of the physical environment was restraining the children's freedom to play and explore outside world. The physical surrounding was pushing the children to become more physically inactive and that is why the parent should not blame in this cases. By making the children stay inside the house will secure their safety as sometimes it was difficult to authorise the children activities outside. The study shows that children in public housing had higher screen time than other children (Salmon et al., 2013). Health issues amongst children are not only due to decreases in physical activities but it is believed that the physical condition of the household also contributes to childhood diseases (van Loon et al., 2014; Vandivere et al., 2006). Small living space in public housing is usually not enough physical area for a family with a huge number of children. This review of this studies is aimed to explore the physical environment that could affect the children physical activities for thus who lives in high-density public housing.

\subsection{Methodology}

A literature review from various disciplines is examined to have a better understanding pertaining the subject matter. It includes understanding the condition of public housing, children physical activities, children psychological development and environmental characteristics. Literature conducted using databases available online such as Science Direct, Scopus, and Web of Knowledge. Keywords given are used as a guideline for literature available online. Both qualitative and quantitative literature are chosen to illustrate the understanding of the knowledge available. The impact on the environmental 
characteristic will influence the physical activity of children and bring an enormous impact on the children outcome in the future.

\subsection{Results and Discussions}

\subsection{Safety}

Children are vulnerable, easily exposed to the danger and adults need to take in mind in accommodating places for both adults and the children. There are three aspects need to be considered in term of safety for children which is the design environment need to be suitable for children, consideration of children capability that differ from the adults and the unpredictable behaviour of the children (Cordovil, Araújo, Pepping, \& Barreiros, 2015).

The poor structural design could harm the children (Vandivere et al., 2006). Most building regulation only highlighted on the core requirement that not stress on the designing purpose and effect. For example, the height of safety railing is $900 \mathrm{~mm}$ horizontally constructed bar which may cause danger when the children are climbing. Lack organised maintenance due to cost imparted are common in public housing. Cheap quit rent taxes can only provide common area maintenance based on a schedule which normally sparse apart. Unattended material and structural may cause harm such as slippery moulded surface, rotten timber, rusted iron, and defect.

Thus, it is important for the adult to consider the design and maintenance aspect to provide safety not only for the adults but also to the children.

Table 1: Neighbourhood major concern on safety factor

\begin{tabular}{|l|l|l|}
\hline Neighbourhood safety & Road Safety & $\begin{array}{l}\text { 1. Speed } \\
\text { 2. Number of cars } \\
\end{array}$ \\
\cline { 2 - 3 } & 3. Road are more vehicle friendly \\
\cline { 2 - 3 } & Stranger & 1. Homeless \\
& Danger & 2. Drug addict \\
& 3. Abduction \\
& 4. Assaults \\
& & 5. Molestion \\
& & 6. Murder \\
\hline
\end{tabular}

Another type of safety that hinder the children physical activities in the neighbourhood safety (Carver et al., 2008; Vandivere et al., 2006). The bad culture of restriction by parents limits the children outdoor activities due to the safety issues and surveillance purpose (Husin, Nawawi, Ismail, \& Khalil, 2012; Mea, 1990; Ramli, Akasah, \& Masirin, 2014; Rudner, 2012). Table 1 shows the two major concern regarding the safety factor which is stranger danger and road safety. Traffic, crime, personal injury, bullying and stranger's 
danger limit their chances to go beyond boundary due to safety reasons (N. F. Aziz \& Said, 2012; Carver, Timperio, Hesketh, \& Crawford, 2010; Latfi \& Karim, 2012; Zhang \& Li, 2012).

Increase number of the car further reduce children activities as they no longer walk and much depend on transportation (Zhang \& Li, 2012). Least to say that road is like a river and barrier compounding children from expanding their range. Plus the environment now day are designed more towards vehicle friendly resulting increases number of accident cases. As a matter of interest, there are cases involving children are reported even in a close gated community leading more parents afraid to allow their children freely without supervision. Majorities of public houses located in urbanised area where surrounded by heavy traffic resulting children who live there are more likely to play along the corridors where there is surveillance by the adults living nearby. Open space provided in public housing are used minimally and contribute less to social interaction particularly between the children (A. A. Aziz \& Ahmad, 2011). Stated in Building By-Law the provision of open space are usually on the ground but never considered vertically in a high-rise. Children who live exposed to the natural outdoor environment can afford to have more independent mobility. Differ from those who lives surrounded by concrete block where natural setting are hard to be found this limiting their social life and play activities (A. A. Aziz \& Ahmad, 2012a).

The awareness of stranger danger includes unwelcome approach by a stranger, abduction, assaults, molestation, and even murder performed by an adult, teenager and also children (Carver et al., 2008). Such crime is often due to the drug, poverty and organised crime and gang-related which are closely related to public housing. As a matter of curiosity, they even live within the community resident itself. As compared to tightly knitted community suspicion amongst parents within the community is very obvious.

When it comes to dependency based on the factor of age and gender, older and male children are more independence as to compare to younger and female children. Lack of dependency are due to younger children are exposed to bullying and self-generated personal injury. Urban parents peculiar public housing haunted by bullying as it generated by peer group and its territory, age and gender difference. Older children look at younger children as weak and intruders that lead to bullying. The gender difference is noticeable with girl having limited space and boundary on an obscure or away from the playing area. Thus, we often see girls playing in or near the house with their fellow friend, sibling or even alone. We can conclude that bullying in a closely related to the high-density resident is due to limited space and amenities which will discuss next.

\subsection{Crowding}

Two aspects of crowding that will be stress on this topic where both characters do give impact toward physical activities as it will then affect the mental and health development of the children. Few researcher agreed on the fact that children in public housing with high number of household are more likely to suffer from crowding which will affect the children wellbeing (Currie \& Yelowitz, 2000; Curtis, Corman, Noonan, \& Reichman, 2010; Leventhal \& Newman, 2010; Ormandy, 2014; Solari \& Mare, 2012). 
First is the crowding among family member where poor housing condition could lead to several health issues such as stomach infection, respiratory and other illnesses (Currie \& Yelowitz, 2000; Vandivere et al., 2006). The number of family member outnumber the physical space or room available could cause stress and adverse consequences among themselves (Solari \& Mare, 2012; Vandivere et al., 2006). It believed that family will have more affect toward the children outcomes as they are much closer in term of physically and socially. Adults that exposed to psychological stress could cause greater conflict between adults and children (Kopko, n.d.; Vandivere et al., 2006). Adult tend to be unresponsive and eventually restraint the parents-child relationship that could affect the children in distress. Plus, decrease social participation amongst family member leads to difficulties to interact with others (Solari \& Mare, 2012). Children's cognitive and language development are also could be affected due to the environment itself that contribute to the intergenerational spread of social inequality as children are more likely to be raised in the multi-level socioeconomic group (Solari \& Mare, 2012).

Second-factor is overcrowding among neighbourhood where resulting negative outcome that affects the children behaviour. Overcrowding forcing the children to make full use of the surrounding accessibility where they might use outdoor neighbourhood environment as a medium of social exploration and development process (A. A. Aziz \& Ahmad, 2012b). The overcrowding neighbourhood is giving no compromise to growing children all due to limited space and in considerable planning for children activity. Children tend to be more distracted with less beneficial play when exposed to the high density of children playing in the same area. Children could experience a lack of self-efficiency and helpless due to crowded spaces that make them have less control over their action and interaction (Vandivere et al., 2006). Limited facilities will hinder them from socialising and explore the neighbourhood places as they need to fight among each other as the majority of the neighbourhood context is fully occupied.

\subsection{Facilities}

Numerous studies have been done to look for residential satisfaction on public housing. Results show that most are satisfied with the public and neighbourhood facilities provided for them (A. A. Aziz \& Ahmad, 2012a; Husin et al., 2012; Karim, 2012; Mohit, Ibrahim, \& Rashid, 2010; Salleh, 2008). Although occupant satisfaction regarding facilities is present, there are still a large number of unsatisfied residents regarding the social environment due to the facilities provided interrelated with the social environment that does not favour them socially. It means that even though facilities are there, it does not contribute to social interaction amongst residents. It shows that the facilities provided are insufficient about the number of residents in or their access to facilities is not well coordinated or not for the automobile culture.

The limitation of public housing is space. Hence, facilities such as playgrounds are often limited provided by the developer (Latfi \& Karim, 2012). Problems arise 
when there are not enough spaces for the children to play around due to the limited land area. Even though the provision of playgrounds ruled by authorities is $10 \%$ of every development in Selangor, it deemed not sufficient enough for development. Especially for multi-storey public housing where the verticality not considered threedimensionally (Latfi \& Karim, 2012). High population density and the playground provided seems to be insufficient or unplanned to them. It will lead to different times spent playing outside in the recreational area between medium and high-density residential. Children that live in high-density public housing tend to spend most of their time indoor. Even when they were allowed to play, it would be limited to the nearby areas. That's why it is often found that children used circulation space as their playing and social area (A. A. Aziz \& Ahmad, 2012b). A recreational area should be conducive for children to gather and play in (Zhang \& Li, 2012). It shows that the lack of complexity provided in playground areas would limit children activities and their creativity to explore (Latfi, Karim, \& Zahari, 2012). Recreational areas should have an environmental attractiveness that promotes more play amongst children (Zhang \& Li, 2011).

Both neighbourhood and public facilities should be accessible to residents. Thus, increase physical activities and social interaction not only among children but also adults in the high-density residential area. High accessibility will enable people to access facilities by foot rather than by transportation. Facilities provided to encourage physical activities among children should be of high visibility to people (Zhang \& Li, 2011). Improved surveillance will reduce the fear of a parent towards the safety of the children.

By providing enough basic and neighbourhood facilities, their daily lives and quality of life will improved (Mohit et al., 2010). The spaces outside the home can encourage more physically and socially active lifestyles (Ivory et al., 2014). Built environment settings play a significant role in ensuring that people are more involved with their neighbours.

\subsection{Neighbourhood relationship}

People living in urban areas often have a busy lifestyle and that they often have limited time to interact and build the relationship with their surrounding neighbours. Such ignorance contributes to low neighbourhood surveillance that poses their home in greater danger. Friendly neighbourhoods provide a friendly environment where all adults know each other and are not afraid to allow their children to play outside. Good neighbourhood relationship is hard to be found nowadays especially in urban areas where people are too busy with work. All adults have a 'mind your own business' mindset with one another resulting in an unfriendly neighbourhood environment. It can give a negative impact on their children. 
When adults don't even know their neighbours, they tend to be more suspicious about their children's safety. As a result, children are not allowed to play outside without supervision that will limit children's independent mobility and sense of security. Without mobility, physical activities will be reduced.

Family and neighbourhood environments influence the behaviour of the children (Salmon et al., 2013) which can relate to physical activity and sedentary behaviour among children. Good neighbourhood relationship can increase social capacity and improve children mobility (A. A. Aziz \& Ahmad, 2012b). They can play around freely as they do not depend on the parent authority or even provide transportation for the children to go (Carver et al., 2008). More time with a neighbourhood area means more time for children to experience social and fewer structured activities (Carver et al., 2008). It is believed to be able to help improve their social ability as they will gather and communicate with one another (Zhang \& Li, 2012).

Public housing with poor neighbourhood characteristic is detrimental for children (Currie \& Yelowitz, 2000) as it will restrict their development (Aziz \& Ahmad, 2012). It believes that the reduction of goods and services in public housing areas are also not safe for children (Currie \& Yelowitz, 2000). What they do not foresee is that neighbourhood activities can provide an inexpensive form of activity (Carver et al., 2008). Poor neighbourhood relationship relates to poor social and physical activity for children to grow. Socialize activity harness the neighbourhood relationship thus increased security (A. A. Aziz \& Ahmad, 2012a) resulting in higher chances of physical activity amongst children.

\subsection{Conclusion}

It has clearly stated that safety, crowding, facilities and neighbourhood relationship play and important role in determining the level of activities for the children. Poor safety, crowding, inadequate facilities and poor neighbourhood relationship will reduce children physical activities and increases the time spent being inactive that could lead to health and social problems in the future.

The physical environment of public housing affects children behaviour regarding children's biological, cognitive, social and emotional development. Physically inactive children due to their low physical activities associated with the poor quality of the physical environment. To cater for their requirements, the built infrastructure for public housing should not stop children's physical activities.

Although the cost is an issue in public housing constructions, a supportive physical environment that support children's physical activities does not necessarily require fancy extras. The adoption of expensive fancy materials or finishes is not the case, but the manipulation of space design that supports play is of the main concern. Space allocation for children to play, be it an outdoor playground or manipulation of corridor layouts in a low-cost public high-rise housing, will significantly enhanced children's physical activities. Children 
are our future generation. Therefore, minimal investment in the physical environment able to maximise their potential to be physically and socially active. The designer needs to become more crucial in designing space that could enhance children's physical activities.

Despite its' poor image, public housing is important for large numbers of a lowincome population. It accommodates places, provides protection and comfort for economically struggling people, which help those that living in urban areas where the cost of living is higher compared to the rural area. Children are vulnerable to their surrounding environment. Lack of access to a good physical environment may inhibit their learning and development processes. Every child despite their economic backgrounds not marginalised in life. All should have equal opportunities to develop properly - physically and mentally. Because children are most vulnerable, designers should not put their future in jeopardy. Public housing should accommodate with an infrastructure that facilitates children growth - it must encourage physical activities. More research regarding the manipulation of the physical environment in low-cost housing needed as an effort to enhance physical activity among children

\section{Acknowledgement}

The Ministry of Education supported these work under the Mybrain15 scholarship awards. Much appreciation toward the anonymous reviewer, supervisor and co-supervisor in providing feedback and detailed suggestion.

\section{References}

Aziz, A. A., \& Ahmad, A. (2011). Flat layouts and children outdoor activities. Asian Journal of EnvironmentBehaviour Studies. Retrieved from http://scholar.google.com/scholar?hl=en\&btnG=Search\&q=intitle:Flat+Layouts+and+Children+Outdoor+Activities\# 0

Aziz, A. A., \& Ahmad, A. S. (2012a). Home Making in Low-Cost Housing Area. Procedia - Social and Behavioral Sciences, 49, 268-281. doi:10.1016/j.sbspro.2012.07.025

Aziz, A. A., \& Ahmad, A. S. (2012b). Low Cost Flats Outdoor Space as Children Social Environment. Procedia Social and Behavioral Sciences, 38, 243-252. doi:10.1016/j.sbspro.2012.03.346

Aziz, N. F., \& Said, I. (2012). The Trends and Influential Factors of Children's Use of Outdoor Environments: A Review. Procedia - Social and Behavioral Sciences, 38, 204-212. doi:10.1016/j.sbspro.2012.03.341

Boldemann, C., Dal, H., Mårtensson, F., Cosco, N., Moore, R., Bieber, B., ... Söderström, M. (2011). Preschool outdoor play environment may combine promotion of children's physical activity and sun protection. Further evidence from Southern Sweden and North Carolina. Science \& Sports, 26(2), 72-82. 
doi:10.1016/j.scispo.2011.01.007

Carver, A., Timperio, A., \& Crawford, D. (2008). Playing it safe: the influence of neighbourhood safety on children's physical activity. A review. Health \& Place, 14(2), 217-27. doi:10.1016/j.healthplace.2007.06.004

Carver, A., Timperio, A., Hesketh, K., \& Crawford, D. (2010). Are children and adolescents less active if parents restrict their physical activity and active transport due to perceived risk? Social Science \& Medicine (1982), 70(11), 1799-805. doi:10.1016/j.socscimed.2010.02.010

Cordovil, R., Araújo, D., Pepping, G.-J., \& Barreiros, J. (2015). An ecological stance on risk and safe behaviors in children: The role of affordances and emergent behaviors. New Ideas in Psychology, 36, 50-59. doi:10.1016/j.newideapsych.2014.10.007

Currie, J., \& Yelowitz, A. (2000). Are public housing projects good for kids? Journal of Public Economics, 75(1), 99-124. doi:10.1016/S0047-2727(99)00065-1

Curtis, M. a, Corman, H., Noonan, K., \& Reichman, N. E. (2010). Effects of child health on housing in the urban U.S. Social Science \& Medicine (1982), 71(12), 2049-56. doi:10.1016/j.socscimed.2010.09.034

Harmon, B. E., Nigg, C. R., Long, C., Amato, K., Anwar, M.-U., Kutchman, E., ... Hill, J. O. (2014). What Matters When Children Play: Influence of Social Cognitive Theory and Perceived Environment on Levels of Physical Activity Among Elementary-Aged Youth. Psychology of Sport and Exercise, 15(3), 272-279. doi:10.1016/j.psychsport.2014.02.001

Husin, H. N., Nawawi, A. H., Ismail, F., \& Khalil, N. (2012). Preliminary Survey of Integrated Safety Elements into Post Occupancy Evaluation for Malaysia's Low Cost Housing. Procedia - Social and Behavioral Sciences, 36, 583-590. doi:10.1016/j.sbspro.2012.03.064

Ivory, V. C., Russell, M., Witten, K., Hooper, C. M., Pearce, J., \& Blakely, T. (2014). What shape is your neighbourhood? Investigating the micro geographies of physical activity. Social Science \& Medicine (1982). doi:10.1016/j.socscimed.2014.11.041

Karim, H. A. (2012). Low Cost Housing Environment: Compromising Quality of Life? Procedia - Social and Behavioral Sciences, 35, 44-53. doi:10.1016/j.sbspro.2012.02.061

Kopko, K. (n.d.). The Effects of the Physical Environment on Children's Development.

Latfi, M. F. M., \& Karim, H. A. (2012). Suitability of Planning Guidelines for Children Playing Spaces. Procedia Social and Behavioral Sciences, 38, 304-314. doi:10.1016/j.sbspro.2012.03.352

Latfi, M. F. M., Karim, H. A., \& Zahari, S. S. (2012). Compromising the Recreational Activities of Children in Low Cost Flats. Procedia - Social and Behavioral Sciences, 50, 791-799. doi:10.1016/j.sbspro.2012.08.081

Leventhal, T., \& Newman, S. (2010). Housing and child development. Children and Youth Services Review, 32(9), 1165-1174. doi:10.1016/j.childyouth.2010.03.008

Mea, H. (1990). One false move... a study of children's independent mobility. London: Policy Studies Institute. Retrieved from http://scholar.google.com/scholar?hl=en\&btnG=Search\&q=intitle:ONE+FALSE+MOVE+...A+Study+of+Children+' +s+Independent+Mobility\#0 
Hanapi, N.L., \& Sh Ahmad, S. / Asian Journal of Quality of Life, AjQoL, 2(5), Jan. / Mar. 2017 (p.1-10)

Mohit, M. A., Ibrahim, M., \& Rashid, Y. R. (2010). Assessment of residential satisfaction in newly designed public low-cost housing in Kuala Lumpur, Malaysia. Habitat International, 34(1), 18-27. doi:10.1016/j.habitatint.2009.04.002

Ormandy, D. (2014). Housing and child health. Paediatrics and Child Health, 24(3), 115-117. doi:10.1016/j.paed.2013.08.009

Ramli, A., Akasah, Z. A., \& Masirin, M. I. M. (2014). Safety and Health Factors Influencing Performance of Malaysian Low-cost Housing: Structural Equation Modeling (SEM) Approach. Procedia - Social and Behavioral Sciences, 129, 475-482. doi:10.1016/j.sbspro.2014.03.703

Rudner, J. (2012). Public knowing of risk and children's independent mobility. Progress in Planning, 78(1), 1-53. doi:10.1016/j.progress.2012.04.001

Salleh, A. G. (2008). Neighbourhood factors in private low-cost housing in Malaysia. Habitat International, 32(4), 485-493. doi:10.1016/j.habitatint.2008.01.002

Salmon, J., Veitch, J., Abbott, G., ChinAPaw, M., Brug, J. J., teVelde, S. J., ... Ball, K. (2013). Are associations between the perceived home and neighbourhood environment and children's physical activity and sedentary behaviour moderated by urban/rural location? Health \& Place, 24, 44-53. doi:10.1016/j.healthplace.2013.07.010

Solari, C. D., \& Mare, R. D. (2012). Housing crowding effects on children's wellbeing. Social Science Research, 41(2), 464-76. doi:10.1016/j.ssresearch.2011.09.012

van Loon, J., Frank, L. D., Nettlefold, L., \& Naylor, P.-J. (2014). Youth physical activity and the neighbourhood environment: examining correlates and the role of neighbourhood definition. Social Science \& Medicine (1982), 104, 107-15. doi:10.1016/j.socscimed.2013.12.013

Vandivere, B. S., Hair, E. C., Theokas, C., Cleveland, K., Mcnamara, M., Atienza, A., \& Vandivere, S. (2006). How Housing Affects Child Well-Being.

Zhang, H., \& Li, M. (2011). Environmental Characteristics of Children's Neighborhood Activities. Asian Journal of Environment-Behaviour Studies.

Zhang, H., \& Li, M.-J. (2012). Environmental Characteristics for Children's Activities in the Neighborhood. Procedia - Social and Behavioral Sciences, 38, 23-30. doi:10.1016/j.sbspro.2012.03.320 